\title{
Pediatric interstitial lung disease masquerading as difficult asthma: Management dilemmas for rare lung disease in children
}

\author{
EY Chan MD MRCP, Sharon D Dell MD FRCPC
}

The cases in this section have been presented by pediatric respiratory residents at monthly video conferences where they were discussed by the trainees and respirologists across Canada. They are published as a result of these proceedings and literature reviews undertaken by the residents

EY Chan, SD Dell. Pediatric interstitial lung disease masquerading as difficult asthma: Management dilemmas for rare lung disease in children. Can Respir J 2005;12(6):317-320.

Idiopathic nontransplant-related childhood bronchiolitis obliterans is an uncommon disease. Most patients present with chronic recurrent dyspnea, cough and wheezing, which are also features of asthma, by far a much more common condition. The present case study reports on a six-year-old girl who presented to a tertiary care centre with recurrent episodes of respiratory distress on a background of baseline tachypnea, chronic hypoxemia and exertional dyspnea. Her past medical history revealed significant lung disease in infancy, including respiratory syncytial virus bronchiolitis and repaired gastroesophageal reflux. She was treated for 'asthma exacerbations' throughout her early childhood years. Bronchiolitis obliterans was subsequently diagnosed with an open lung biopsy. She did not have sustained improvement with systemic corticosteroids, hydroxychloroquine or clarithromycin. Cardiac catheterization confirmed the presence of secondary pulmonary hypertension. Treatment options remain a dilemma for this patient because there is no known effective treatment for this condition, and the natural history is not well understood. The present case demonstrates the need for careful workup in 'atypical asthma', and the urgent need for further research into the rare lung diseases of childhood.

Key Words: Bronchiolitis obliterans; Difficult asthma; Pediatric interstitial lung disease
Une pneumopathie interstitielle pédiatrique déguisée en asthme difficile : Les dilemmes de prise en charge d'une pneumopathie rare chez les enfants

\begin{abstract}
La bronchiolite oblitérante infantile idiopathique non reliée à une greffe est une maladie rare. La plupart des patients souffrent de dyspnée récurrente, de toux et de wheezing, également caractéristiques de l'asthme, beaucoup plus courante. La présente étude de cas fait état d'une fillette de six ans qui est arrivée à un centre de soins tertiaires à cause d'épisodes récurrents de détresse respiratoire sur fond de tachypnée de base, d'hypoxémie chronique et de dyspnée à l'effort. Ses antécédents médicaux révélaient une pneumopathie importante pendant la première enfance, y compris une bronchiolite à virus respiratoire syncytial et un reflux gastro-œsophagien réparé. Elle avait été traitée pour des « exacerbations de l'asthme » tout au long de sa première enfance. Une bronchiolite oblitérante avait ensuite été diagnostiquée grâce à une biopsie pulmonaire chirurgicale. Elle n'avait pas profité d'améliorations soutenues grâce aux corticoïdes systémiques, à l'hydrochloroquine ou à la clarithromycine. Un cathétérisme cardiaque a confirmé la présence d'hypertension pulmonaire secondaire. Les possibilités de traitement sont demeurées un dilemme pour cette patiente parce qu'il n'existe pas de traitement efficace connu de cette maladie, dont l'évolution naturelle n'est pas bien comprise. Le présent cas démontre la nécessité de procéder à un bilan attentif en cas d' « asthme atypique » et le besoin urgent de recherches supplémentaires sur les pneumopathies rares de l'enfance.
\end{abstract}

Division of Respiratory Medicine, The Hospital for Sick Children, Toronto, Ontario

Correspondence: Dr Sharon Dell, Division of Respiratory Medicine, The Hospital for Sick Children, 555 University Avenue, Toronto, Ontario M5G 1X8. Telephone 416-813-6248, fax 416-813-6246, e-mail sharon.dell@sickkids.ca

\section{AstraZeneca}


A lthough asthma remains the most common cause of recurrent wheezing and respiratory distress in children, the present case highlights the importance of exploring alternative diagnoses in cases of 'difficult asthma' that do not respond to conventional treatment.

Although there are vast differential diagnoses, pediatric interstitial lung disease (pILD) is one of the main considerations in the face of long-standing tachypnea and hypoxemia. The term 'pILD' encompasses a heterogeneous group of rare lung disorders in children (1). Invasive procedures, including lung biopsy, are usually required for diagnosis, albeit with suboptimal yield (2). Therapeutic options have generally not been systematically studied and have limited success. Furthermore, the natural history of these disorders is not well understood because of a lack of longitudinal data for these conditions.

\section{CASE PRESENTATION}

A six-year-old African Canadian girl with a past history of asthma presented to her local community hospital with a one-week history of shortness of breath, cough and coryzal symptoms. She had little improvement after one week of outpatient treatment with prednisone, regular salbutamol and fluticasone. A diagnosis of pneumonia on the background of asthma was made. Inpatient treatment at her local hospital included oxygen, cefuroxime, clarithromycin, hydrocortisone, salbutamol and ipratropium bromide. Due to a lack of significant improvement and marked ongoing hypoxemia, she was transferred the following week to the authors' tertiary care centre for further investigation.

Physical examination revealed marked finger clubbing, increased work of breathing (tracheal tug, nasal flaring and a respiratory rate of 38 breaths/min) and hypoxia (oxygen saturation rapidly dropped to less than $80 \%$ in room air) in a small, afebrile child with a weight in the 10th percentile and a height in the 50th percentile for her age. On auscultation of the lung fields, there was reduced air entry to both bases, bilateral basal crackles and wheezing. Heart sounds were normal. The liver was palpable $3 \mathrm{~cm}$ below the costal margin. There was no evidence of rash or joint swelling.

The patient had a long history of tachypnea and shortness of breath on exertion. Her past medical history included multiple hospitalizations with respiratory distress since infancy, with the first hospital admission at two months of age for respiratory syncytial virus (RSV) bronchiolitis. She was diagnosed with gastroesophageal reflux at 10 months of age, resulting in fundoplication and three months of gastrostomy tube feeding. Following this, her subsequent hospital admissions (at ages three and four years) with respiratory distress were treated as asthma exacerbations. Her maintenance therapy included inhaled salbutamol and fluticasone. Her family history and birth history were unremarkable.

Baseline bloodwork including complete blood count, clotting indexes, erythrocyte sedimentation rate, electrolyte and liver function tests was normal except for an elevated hemoglobin level $(155 \mathrm{~g} / \mathrm{L})$ reflecting chronic hypoxemia. Her capillary blood gas revealed a $\mathrm{pH}$ of 7.45 and partial pressure of carbon dioxide of $50 \mathrm{mmHg}$. Diagnostic imaging including chest radiograph (Figure 1) and high-resolution computed tomography (HRCT) (Figure 2) was performed and showed diffuse changes suggestive of pILD. Her sweat test, immune workup (including immunoglobulin [Ig] subclasses, functional antibody studies, $\mathrm{T}$ and $\mathrm{B}$ cell markers and stimulation tests)

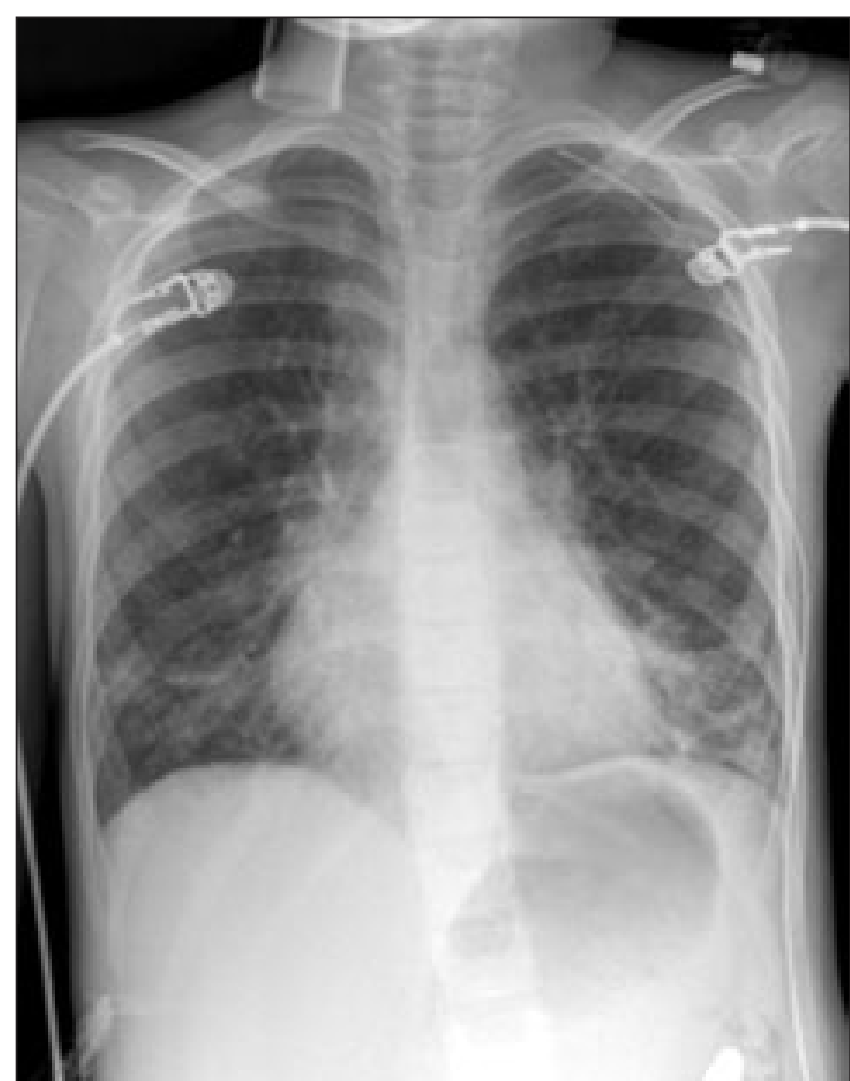

Figure 1) Chest radiograph on admission showing hyperinflation and bilateral linear opacities throughout the lungs, particularly in the bases

and HIV serology were negative. Sputum culture and nasopharyngeal swab for respiratory viruses were also negative. Serology was positive for Epstein-Barr virus (EBV) viral capsid antigen and EBV nuclear antigen $\operatorname{IgG}$, indicating past EBV infection. Her first spirometry test showed what initially appeared to be a restrictive pattern (forced vital capacity was $41 \%$ predicted and forced expiratory volume in $1 \mathrm{~s}$ was $39 \%$ predicted). She was unable to perform lung volume tests at that time. The echocardiogram showed bowing of the right atrial septum to the left, and a right ventricle-right atrium gradient of $40 \mathrm{mmHg}$, indicating pulmonary hypertension.

An open lung biopsy was performed. Histology revealed bronchioles with varying degrees of narrowing associated with smooth muscle hypertrophy and peribronchiolar fibrosis. Alveolar septae were thickened by extensive fibrous tissue. The features were in keeping with bronchiolitis obliterans (BO) (Figure 3). The histology specimen was negative by immunofluorescence for RSV, cytomegalovirus (CMV), varicellazoster virus and adenovirus, but positive for EBV by polymerase chain reaction.

The patient was treated with prednisone and a six-week course of gancyclovir on the basis of the positive EBV nuclear antigen and viral capsid antigen IgG. She was discharged home on prednisone, salbutamol, fluticasone and nasal prong oxygen at $3 \mathrm{~L} / \mathrm{min}$.

In her subsequent follow-up one month later, lung function tests revealed some improvement in flows with a forced expiratory volume in $1 \mathrm{~s}$ of $49 \%$ predicted. She had normal resting lung volumes (total lung capacity was $103 \%$ predicted) with significant gas trapping (residual volume/total lung capacity 


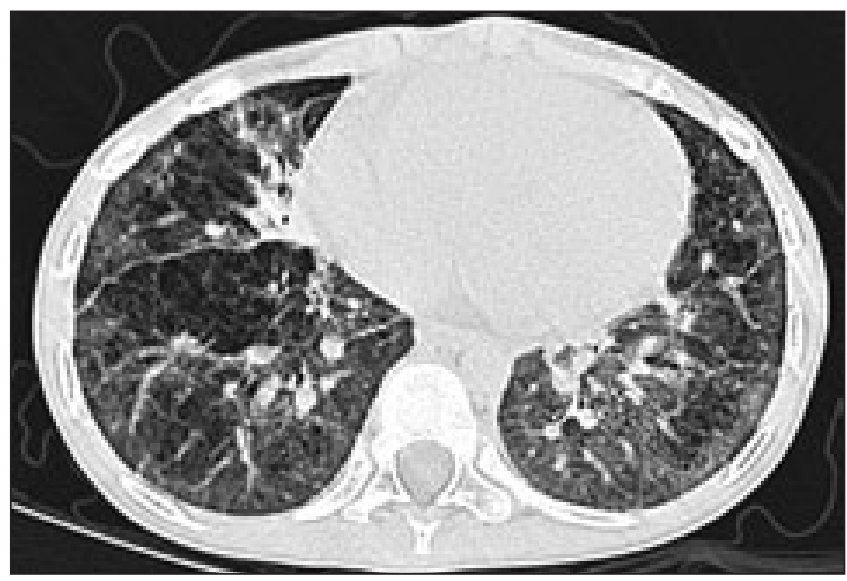

Figure 2) High-resolution computed tomography showing diffuse ground glass opacities involving both lungs with gas trapping and marked interstitial thickening involving the lobular septae

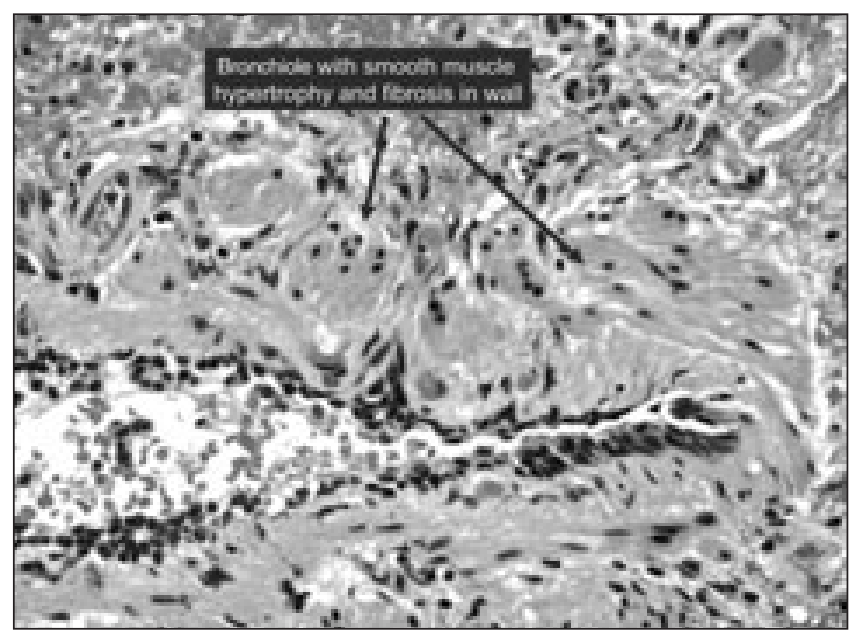

Figure 3) Histology of lung biopsy showing smooth muscle hypertrophy and obliteration of bronchioles by fibrous tissue

was $47 \%$ and forced vital capacity was $67 \%$ predicted) and an obstructive pattern. She was commenced on oral hydroxychloroquine at a dose of $10 \mathrm{mg} / \mathrm{kg}$ with a view to wean her steroid dose because she was cushingoid by this time. However, her clinical course waxed and waned, requiring the adjustment of steroid dosing down and up in response. She remained very hypoxic and dependent on continuous high-flow oxygen. A six-week trial of high-dose clarithromycin was unhelpful. She underwent cardiac catheterization to exclude extracardiac shunting. This revealed a mean pulmonary artery pressure of $30 \mathrm{mmHg}$, with maximal improvement on 100\% oxygen when pulmonary artery pressure dropped to $24 \mathrm{mmHg}$.

Overall, oral maintenance steroids and hydroxychloroquine have not produced a substantial clinical improvement in the patient. She remains hypoxic with secondary pulmonary hypertension.

\section{DISCUSSION}

$\mathrm{BO}$ is a rare condition in childhood. It is histologically defined by inflammation and fibrosis occurring predominantly in the walls and contiguous tissues of membranous and respiratory
TABLE 1

\section{Etiologies of bronchiolitis obliterans}

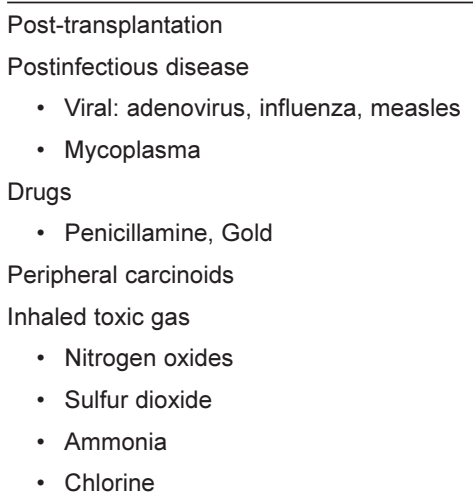

Autoimmune disease

- Rheumatoid arthritis

- Ulcerative colitis

- Psoriatic arthritis

- Pemphigus vulgaris

Recurrent aspiration

Idiopathic

bronchioles, thus resulting in narrowing of the lumens (3). $\mathrm{BO}$ has diverse etiologies (4) (Table 1), of which the most common are post-transplantation-related and postinfectious. Certain Aboriginal populations seem to be particularly susceptible to postadenovirus $\mathrm{BO}(5,6)$.

In the case of our patient, infection and recurrent aspirations are potential etiologies. $\mathrm{BO}$ as a sequela to adenovirus (types 3 , 7 and 21), influenza A, measles and mycoplasma infections has been well documented (7-10). Our patient had previously documented RSV bronchiolitis; however, we do not know whether other viruses, such as adenovirus, were tested for. Although RSV infection alone has not been reported to cause $\mathrm{BO}$, coinfection with RSV and adenovirus has been described as a precursor to BO (11). Our patient also had serological evidence of previous EBV infection. The association of EBV infection with $\mathrm{BO}$ in immunocompetent, nontransplant, pediatric patients has not been reported. Adult studies (12) have suggested an association between EBV infection and idiopathic pulmonary fibrosis. In immunocompetent children, pulmonary parenchymal involvement in acute EBV infection is thought to be uncommon, although there have been a few case reports $(13,14)$ linking EBV infection with interstitial lung disease in infancy. Whether EBV was the pathogen or a 'passenger' is not clear.

Histology provides the gold standard for diagnosing BO. The characteristic patchy lesions make sampling by transbronchial biopsy difficult. The diagnostic yield using open lung biopsy or video-assisted thoracoscopy is far superior $(2,15)$. HRCT is another useful tool for diagnosing $\mathrm{BO}$, with the sensitivity and specificity reported to be $80 \%$ to $93 \%$ and $80 \%$ to $94 \%$, respectively (16-18). The characteristic 'mosaic pattern' results from gas trapping distal to the narrowed bronchioles, leading to parenchymal distortion and subsequent decreased perfusion to areas with bronchiolar obstruction. However, it should be noted that neither the pathological changes $(19,20)$ nor the extent of abnormalities on HRCT (21) correlates well with the functional impairment of the patients. 
The clinical course of $\mathrm{BO}$ is not well documented in the literature because no prospective longitudinal studies have been performed. In one retrospective series of postinfectious $\mathrm{BO}$ patients (aged two to nine years) (22), 23\% of patients went into remission and $68 \%$ had persistent symptoms 3.5 years later. Infectious exacerbations associated with $\mathrm{BO}$ are a major cause of morbidity and mortality (23). The severity of the illness, as marked by the presence of hypoxemia and pulmonary hypertension, is generally associated with poor survival in children with pILD (24).

The treatment of idiopathic $\mathrm{BO}$ is supportive. Supplemental oxygen, bronchodilators and corticosteroids are the mainstay of therapy, although there have been no controlled trials on the use of steroids in children with $\mathrm{BO}$. In the postlung transplantation population, where recurrent rejection, and EBV and CMV infections are thought to be risk factors for developing $\mathrm{BO}$, treatment strategies include augmentation of immunosuppression (using cyclosporin A, azathioprine and OKT3), early aggressive treatment of infections and prophylaxis for CMV and EBV infection using gancyclovir (25). Lung transplantation is an option for end-stage lung disease.

From the practical point of view, the treatment options for our patient remain a dilemma. Oxygen therapy, systemic

\section{REFERENCES}

1. Fan LL, Langston C. Chronic interstitial lung disease in children. Pediatr Pulmonol 1993;16:184-96.

2. Fan LL, Kozinetz CA, Wojtczak HA, Chatfield BA, Cohen AH, Rothenberg SS. Diagnostic value of transbronchial, thoracoscopic, and open lung biopsy in immunocompetent children with chronic interstitial lung disease. J Pediatr 1997;131:565-9.

3. Myers JL, Colby TV. Pathologic manifestations of bronchiolitis, constrictive bronchiolitis, cryptogenic organizing pneumonia, and diffuse panbronchiolitis. Clin Chest Med 1993;14:611-22.

4. Ryu JH, Myers JL, Swensen SJ. Bronchiolar disorders. Am J Respir Crit Care Med 2003;168:1277-92.

5. Wenman WM, Pagtakhan RD, Reed MH, Chernick V, Albritton W. Adenovirus bronchiolitis in Manitoba: Epidemiologic, clinical, and radiologic features. Chest 1982;81:605-9.

6. Teper AM. Association between HLA and incidence of bronchiolitis obliterans (BO) in Argentina. Am J Respir Crit Care Med 2004;169:A382. (Abst)

7. Milner AD, Murray M. Acute bronchiolitis in infancy: Treatment and prognosis. Thorax 1989;44:1-5.

8. Kim CK, Kim SW, Kim JS, et al. Bronchiolitis obliterans in the 1990s in Korea and the United States. Chest 2001;120:1101-6.

9. Panitch HB, Callahan CW Jr, Schidlow DV. Bronchiolitis in children. Clin Chest Med 1993;14:715-31.

10. Chan PW, Muridan R, Debruyne JA. Bronchiolitis obliterans in children: Clinical profile and diagnosis. Respirology 2000;5:369-75.

11. Massie R, Armstrong D. Bronchiectasis and bronchiolitis obliterans post respiratory syncytial virus infection: Think again. J Paediatr Child Health 1999;35:497-8.

12. Stewart JP, Egan JJ, Ross AJ, et al. The detection of Epstein-Barr virus DNA in lung tissue from patients with idiopathic pulmonary fibrosis. Am J Respir Crit Care Med 1999;159:1336-41.

13. Ankermann T, Claviez A, Wagner HJ, Krams M, Riedel F. Chronic interstitial lung disease with lung fibrosis in a girl: Uncommon sequelae of Epstein-Barr virus infection. Pediatr Pulmonol 2003;35:234-8. corticosteroids and hydroxychloroquine have not produced substantial improvement. Pulse intravenous steroid therapy is an option but must be used cautiously in the face of pulmonary hypertension, and is unlikely to have a large additional benefit with the extensive fibrosis already present. Lung transplantation is an option which can potentially provide an improvement in function and quality of life for a finite period of time. The timing of transplantation is debatable because the natural history of this disease is not well understood. The present case illustrates our current lack of understanding of rare morbid lung diseases in children. Further research is necessary to determine the pathogenesis, natural history and new treatment options for these conditions.

ACKNOWLEDGEMENTS: The authors thank Dr Ernest Cutz and $\mathrm{Dr}$ Gino Somers for their assistance in providing the pathology print.

SUPPORT: The Cross Canada Pediatric Respiratory Group wishes to acknowledge AstraZeneca for their ongoing support of this program. The assistance provided in the establishment and development of these rounds, the first of this nature in the world, is greatly appreciated by the pediatric respiratory community.

14. Pfleger A, Eber E, Popper H, Zach MS. Chronic interstitial lung disease due to Epstein-Barr virus infection in two infants. Eur Respir J 2000;15:803-6.

15. Fan LL, Kozinetz CA, Deterding RR, Brugman SM. Evaluation of a diagnostic approach to pediatric interstitial lung disease. Pediatrics 1998;101:82-5.

16. Leung AN, Fisher K, Valentine V, et al. Bronchiolitis obliterans after lung transplantation: Detection using expiratory HRCT. Chest 1998;113:365-70.

17. Worthy SA, Park CS, Kim JS, Muller NL. Bronchiolitis obliterans after lung transplantation: High-resolution CT findings in 15 patients. AJR Am J Roentgenol 1997;169:673-7.

18. Ikonen T, Kivisaari L, Harjula AL, et al. Value of high-resolution computed tomography in routine evaluation of lung transplantation recipients during development of bronchiolitis obliterans syndrome. J Heart Lung Transplant 1996;15:587-95.

19. Colby TV, Myers JL. Clinical and histologic spectrum of bronchiolitis obliterans, including bronchiolitis obliterans organizing pneumonia. Semin Resp Med 1992;13:119-33.

20. Markopoulo KD, Cool CD, Elliot TL, et al. Obliterative bronchiolitis: Varying presentations and clinicopathological correlation. Eur Respir J 2002;19:20-30.

21. Padley SP, Adler BD, Hansell DM, Muller NL. Bronchiolitis obliterans: High resolution CT findings and correlation with pulmonary function tests. Clin Radiol 1993;47:236-40.

22. Zhang L, Irion K, Kozakewich H, et al. Clinical course of postinfectious bronchiolitis obliterans. Pediatr Pulmonol 2000;29:341-50.

23. Paradis I. Bronchiolitis obliterans: Pathogenesis, prevention, and management. Am J Med Sci 1998;315:161-78.

24. Fan LL, Kozinetz CA. Factors influencing survival in children with chronic interstitial lung disease. Am J Respir Crit Care Med 1997;156:939-42.

25. Bando K, Paradis IL, Similo S, et al. Obliterative bronchiolitis after lung and heart-lung transplantation. An analysis of risk factors and management. J Thorac Cardiovasc Surg 1995;110:4-13. 


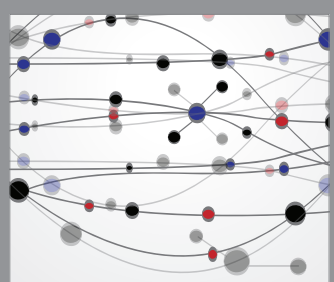

The Scientific World Journal
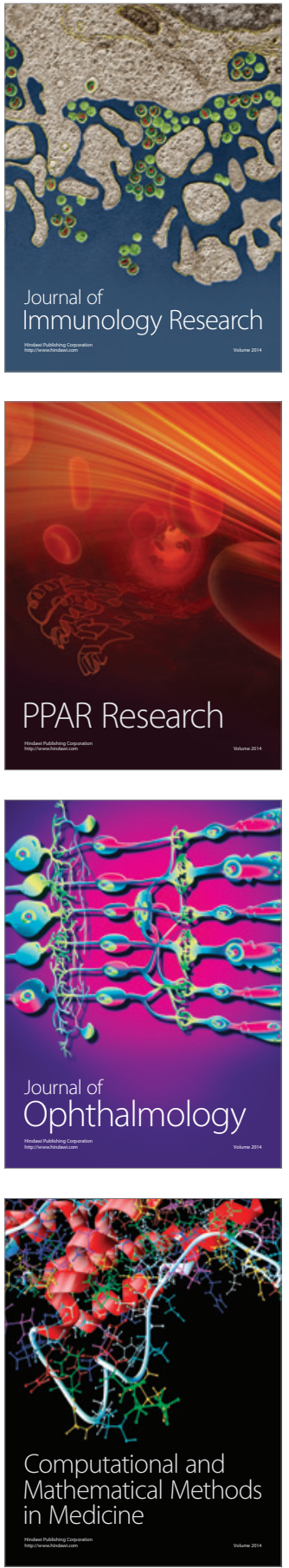

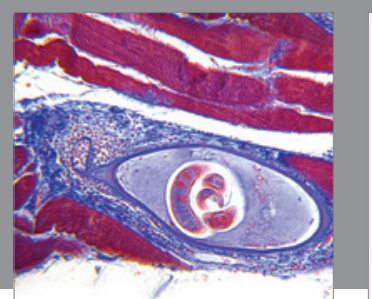

Gastroenterology Research and Practice

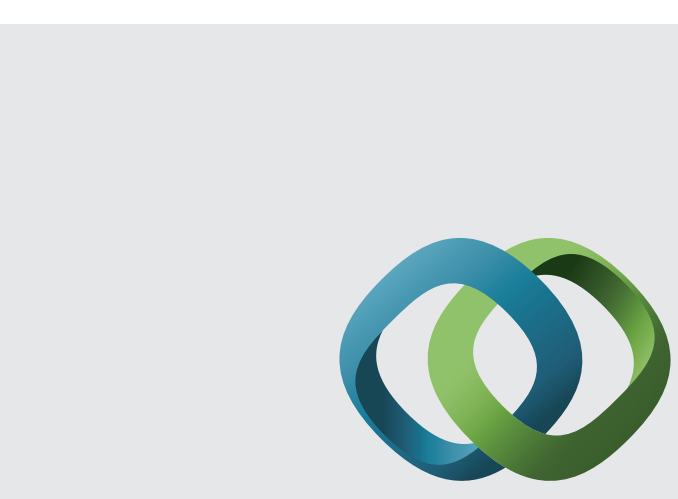

\section{Hindawi}

Submit your manuscripts at

http://www.hindawi.com
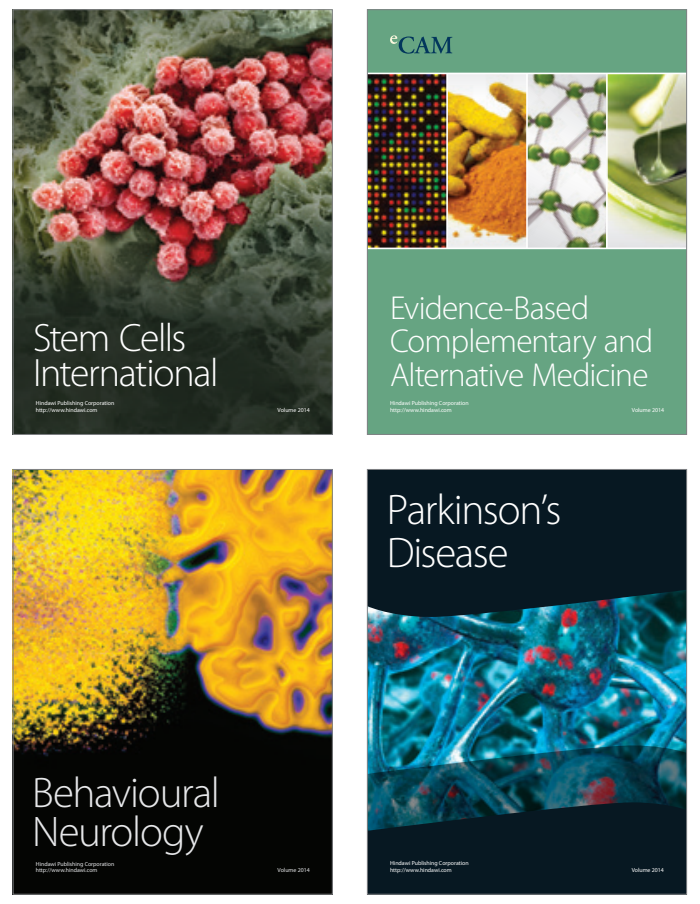
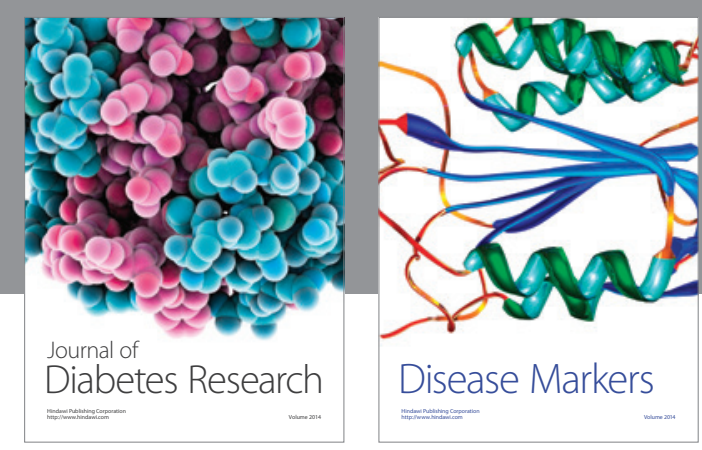

Disease Markers
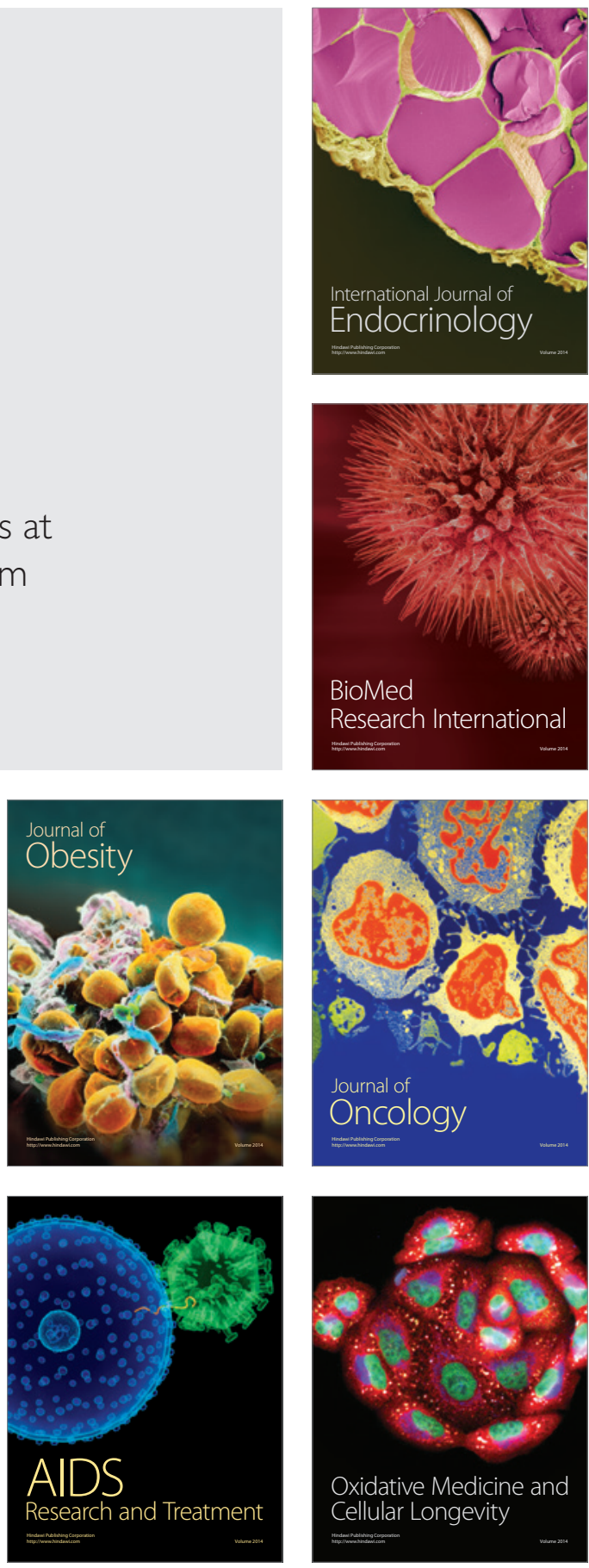